\title{
Public Private Partnership in the Provision of Health Services for the Millennium Development Goals: The Imperative Need for Optimizing the Public-Private Mix
}

\author{
Maximus N. O. Asogwa, PhD \\ Department of Public Administration and Local Government, University of \\ Nigeria, Nsukka \\ Severus I. Odoziobodo, PhD \\ Department of Political Science, Enugu State University of Science and \\ Technology, Enugu
}

doi: 10.19044/esj.2016.v12n29p175 URL:http://dx.doi.org/10.19044/esj.2016.v12n29p175

\begin{abstract}
Nigeria, with its large public sector, equally has an extensive wellestablished private sector; even with the ravages of the recent economic crisis. Both sectors play complementary and important roles as providers of expertise and as implementing agencies. Public-Private Partnership (PPP), the paper posits, is therefore an effort where the government of Nigeria provides the minimum standards required for coordinated collaboration with private sector, in the case of this study, the health sector. Notwithstanding various investment efforts from the public and private sectors into the Nigeria health economy, the performance of the national health system remains deplorable. The paper believes that the declining resource allocation to health, increasing costs and the breakdown in the public health facilities, make the achievement of health-related MDGs', Millennium Development Goals', (now SDGs, Sustainable Development Goals') targets difficult. It is on the basis of this that the study, examines the pattern and scope of existing collaborations, including the nature, distribution of stakeholders in the sector and the characteristics of PPP in the health sector. It also examines the challenges, options and potentials for future partnership. These are examined within the strategic framework of MDGs and suggestions are made on how to overcome the challenges of public-private interventions to ensure effective policy interventions in the current Sustainable Development Goals, SDGs.
\end{abstract}

Keywords: Health sector, Public sector, private sector, partnership, Millennium Development Goals 


\section{Introduction}

Government and the private sector have historically worked together on a wide range of issues including setting regulatory frameworks, implementing development programmes, and other public policy decisions that affect the economy and society. Thus, governments all over the world are turning to public-private partnership (otherwise known as PPP) as a means of improving public services and meeting the investment challenges that they face. In the context of this paper, PPP means any collaboration between public bodies (central and sub-national governments) and the private sector (private companies or institutions, religious or faith-based organizations, Non-Governmental Organizations (NGOs) in the development and funding of health care facilities and institutions.

The introduction of PPP as a standard tool for the provision of public service and infrastructure is becoming increasingly common in Africa, just as it has been in most developed countries, especially, Europe, where such policies are directly linked to long-term economic growth/stability; and breed mutual benefits. In all these places, PPP covers a wide range of partnerships including the Private Finance Initiative (PFI), the introduction of services into wider markets, and other partnership arrangements where private sector expertise in the finance are used to exploit the commercial potential of government assets.

PPP is not a new model in Nigeria. However, the extent of publicprivate partnership in any country is critically dependent on the nature of economic governance, which may be state-dominated economy, mixed economy or market economy. What has extended the frontiers of publicprivate partnerships in Nigeria and many developing countries are the liberalization and deregulation measures adopted as part of economic reforms driven largely by privatization of State-Owned Enterprises (SOES). Privatization has been implemented in Nigeria not only for budgetary considerations but also to reduce the scope of active government involvement in the productive sectors of the economy; in other words, a movement from state-led economy to a more market-oriented economy.

The basic challenge has always been the absence of effective mechanism to combine the diverse skills, expertise and varied resources within an effective policy framework of defined roles, and responsibilities for a common goal improvement of the health status of Nigerians. What do we know about existing collaboration between the private and public sector in the health sectors? What are the challenges of implementing the national PPP in the health sector? What are the potentials of PPP policy in the delivery of MDGs health-related targets? This paper addresses these issues. 


\section{The Problem}

In recent years, there has been a dramatic increase in the involvement of the private sector, alongside contributions from development partners and civil society organizations in the development and funding of public facilities and services. Techniques are continuously being developed to draw the public and private sectors together. In the Nigerian health system, the publicprivate partnerships initiative has been a financing strategy or gateway that involves the employment or mobilization of private sector capital to put up health care infrastructure and services to improve public health activities/services, or the management of public sector health resources. Arin Dutta, et al (2009) corroborate this claim when they note that: "partnerships between the public and private sector in scaling up health service delivery are currently being discussed in many countries, and actively so in Nigeria. There are several possible financing modalities in such public-private partnerships, such as the public sector - i.e., the government - playing a stewardship or regulatory role but not financing private sector provision or the participation of the private sector in government-subsidized risk-pooling mechanisms for the poor. In terms of specific responsibilities in service delivery, there is a general view that the public health sector will continue to have a major role in providing preventive and primary health care, where user fees are not suitable from a public health perspective, or where clients have reduced ability or willingness to pay. The private sector would have a role in curative as well as maternal and child health services, especially in urban areas and for those with the ability to pay".

Arin Dutta, et al (2009) also note that there is little public-private coordination in health care service delivery in Nigeria that corresponds to the understanding stated above and in addition, there is no coordination or in the management of human resources for health $(\mathrm{HRH})$. Yet, the importance of such coordination has been raised in some broader studies that indicate that involving the private sector in scale-up is inescapable. The reasoning in some studies is that a substantial portion of health care provision already comes from the private sector, Dutta, et al (2009). For example, an assessment by the International Finance Corporation (IFC) reported that up to half of all health service provision in Africa occurs through the private sector (IFC 2007a). Dutta et al (2009) note however, that other studies debate the significance of the private sector's contribution to service delivery, and hence, raise into question, the merits of enhanced coordination. A study, which claims to utilize the same IFC data, finds that 40 percent of the private sector's provision of services is through small shops selling drugs - implying 
that only 60 percent of the identified scale of provision is through a formal health facility (Oxfam International 2009).

Nigeria, no doubt, recognizes the right to health and has committed itself to its protection by assuming obligation under international treaties and domestic legislations mandating specific conduct with respect to the health of individuals within its jurisdiction. Prior to the economic travails of the mid 1980s, the health sector witnessed robust growth, principally as a result of adequate support by the government, with assistance from international partners. Nnamuchi (2007) notes that prior to the mid-1980s, access to health care was available at public hospitals and clinics, usually at no cost or highly subsidized rate, except in the rural areas. This is no longer the case today and Nnamuchi (2007) points accusing finger at the venal governance of that momentous historical period during which kleptomaniac repressive military dictatorship led to widespread corruption and mismanagement of that era. This was the period, when basic public health infrastructure, medical treatment and consultation in public health facilities, where available, were unaffordable to most people (Transparency International, 2004; UN, 2007).

The exit of the military in 1999 came with unprecedented expectations and rekindled hope for a change in status quo. Perhaps, as a result, the democratically elected administrations introduced several innovative policy measures some of which are presently being implemented at the different levels of government aimed at restructuring and revamping the health systems, and concomitantly, realizing the goals of the revised National Health Policy and health-related goals of the Millennium Development Goals (MDGs), such as reducing child mortality, improving maternal health and combating HIV/AIDS, malaria and other infectious diseases.

However, despite such measures adopted by civilian regimes since 1999, the performance of the health system remains unsatisfactory. This state of affairs has been attributed to many reasons, particularly, health financing. According to UNDP (2005), government expenditure on health as a percentage of GDP, was $1.3 \%$ in 2003, a decline from $2.2 \%$ in 2000 (WHO, 2007). With regard to government expenditure as a percentage of total expenditure on health, the Nigerian government's share declined from $29.1 \%$ in 1999 to $25.5 \%$ in 2003 (WHO, 2006), lagging behind many other countries, even those similarly classified by the World Bank as low income economies. For example, within the same period, the share of governments of Senegal, Ethiopia and Sierra Leone, improved to $41.8 \%, 58.4 \%$ and $58.3 \%$ respectively (WHO, 2006). A more startling revelation is that in per capita terms, public spending on health stands at less than $\$ 5$, and in some parts of the country, can be as low as $\$ 2$, far short of the $\$ 34$ recommended 
by WHO for low income countries within the Macroeconomic Commission Report (WHO, 2007). In addition, there is the concern that the budgeted figures may not be a true representative of the actual amount spent on health, as there are in most cases, a gap between the two figures (WHO, 2007). Apparently, this level of expenditure made it difficult to achieve the MDGs on health.

The declining resource allocations to health, increasing costs, and the ever increasing expectations from the public for better services appear to have worsened the situation. It is not then surprising that progress reports on MDGs in Nigeria were not favourable in all health-related goals. While the 2004 report stated that it was unlikely that the country will be able to meet the goals of reducing child mortality and maternal mortality and combating HIV/AIDS, malaria and other diseases (FRN, 2004), the 2005 MDGs Report was less optimistic about the MDGs targets on reducing child mortality, improving maternal health and combating HIV/AIDS, malaria and other diseases (FRN 2005). Same applied to the 2006 Report which specifically raised concern about the slow pace to the MDGs targets on the above healthrelated goals (FRN, 2006). These reports were collaborated by the United Nations Human Development Report 2010 which also offered scary details about the possibility of being able to combat diseases effectively and reduce maternal mortality. The report put Nigeria's life expectancy at birth at 48.4 years, a little above the 47.7 years recorded for the country's Human Development Index (HDI) at 0.423 , making the country 142 out of 169 countries with comparable data (UN. 2010).

One of the key challenges has always been the absence of effective mechanisms to combine different skills, expertise and other resources within an effective policy framework of defined roles.

\section{Theoretical foundation of the study}

Public-private partnership rests on three arguments: the political, the social and the business (Hofman, 1990). The political case arises from the justification of the private sector as a more efficient manager of resources than the public sector. The public-private partnership is therefore said to introduce private sector efficiencies into public service by means of a contractual agreement, timelines in the implementation of projects and risk mitigation as well as the use of innovative private finance initiatives (PFIs) not previously available to the public sector in the financing and implementation of key public sector projects and programmes, especially infrastructure and related service projects.

The social case for PPP can be seen from at least two major perspectives. 
1. The positive impact of successfully implemented PPP projects on public finance, public sector resource constraint and good economic governance/accountable and transparent governance.

2. The successful application of PPP as a financing and infrastructural procurement model and strategy in many countries like China and South Africa in the health education and housing sectors, with all the benefits of cost-effectiveness, timeliness in project delivery and a high quality of service delivery.

Finally, the Business/Economic case for PPP in Nigeria is based on the strategic role of the private sector as the prime mover and engine of growth of the economy. For example, the key reason for the breath-taking economic development in India has been the active involvement of the private sector in the delivery of PPP projects in the country (Preker and Harding, 2000). It is expected that the same can be achieved in Nigeria with governments at all levels and the private sector financiers and contractors working together in partnership. The effect would be to expand the portfolio and scope of investment opportunities available to the private sector, thereby creating wealth and urgently needed employment opportunities.

\section{An overview of public-private partnership in the health sector}

The structure and organization of the health system in Nigeria is a complex one. This is because it includes a wide range of providers, comprising the public and a large and burgeoning private sector made up of private for profit and private not-for-profit providers (NGOs, communitybased organizations, religious/spiritual and traditional care providers). Other private health sector actors include various professional associations. One significant issue of note is that the mandate of the Federal Ministry of Health and other tiers of government are not captured either in the constitution or in any law under the present health care delivery arrangements in Nigeria. The 1999 constitution is ambiguous on the responsibilities for health care delivery except the vague reference made with regard to local government responsibility for health. However, the National Health Bill of 2004 addressed these gaps with relevant provision for the respective roles of each tier of government. In practice, the health system is decentralized under a federal structure. The federal level is responsible for secondary services; the state level is responsible for secondary services and the local governments for primary services.

Available data from the Federal Ministry of Health record for 2005 indicate that the tertiary level, the Federal Government operates 19 teaching and specialist hospitals, eight psychiatric hospitals and three orthopedic hospitals, as well as 24 Federal Medical Centres/staff hospitals distributed among the states. There were three private sector tertiary hospitals in the 
country within the period. It will be appreciated that having 57 tertiary and specialized hospitals to an estimated 140 million Nigerians suggests poor access to a higher level of referral service (Matazu, 2005). Furthermore, the World Bank (2005) stated that in 2000, there were 855 public sector secondary facilities with a population to facility ratio of around 13:5000. Equally, there existed 2,147 privately operated facilities, bringing the total to 3002 secondary facilities in the country.

In terms of spatial distribution of health facilities in the country, there are considerable disparities with significant fewer hospitals in the North than in the southern part of the country. The reason for this disparity has been attributable to the greater number of private secondary hospital facilities in the south vis-à-vis that of the North. Significantly, private providers account for $72 \%$ of the whole secondary facilities: but only $5 \%$ in the Northeast and $24 \%$ in the Northwest, compared to over $90 \%$ in the Southeast and over $80 \%$ in the South-south and Southwest. And in the North central zone, just half of secondary facilities are of the private sector (World Bank, 2005).

The above has been collaborated by the report of National Bureau of Statistic in the Nigeria Poverty Assessment 2007 (see table below). It is reported that health facilities are unevenly distributed in Nigeria as larger concentration of secondary facilities are located in the South, especially Southeast. So, while majority of secondary care facilities in the Northern region are public, the opposite is the case for the Southern States (NBS, 2007).

Population Per Health Facility Across Geo-Political Zones.

$\begin{array}{llccc}\begin{array}{l}\text { Geo-political } \\ \text { Zone }\end{array} & \begin{array}{l}\text { Primary Population } \\ \text { per facility }\end{array} & \text { \%Public } & \begin{array}{l}\text { Secondary } \\ \text { per facility }\end{array} & \text { Population \%Public } \\ \text { North Central } & 3,205 & 62 \% & 40,729 & 57 \% \\ \text { North East } & 6,234 & 86 \% & 162,355 & 95 \% \\ \text { North West } & 7,170 & 91 \% & 199,181 & 76 \% \\ \text { South East } & 5,437 & 35 \% & 12,506 & 8 \% \\ \text { South South } & 6,854 & 67 \% & 25,213 & 28 \% \\ \text { South West } & 5,421 & 54 \% & 29,566 & 26 \% \\ \text { Nigeria } & 5,585 & 67 \% & 38,383 & 28 \%\end{array}$

Source: NBS, 2007 (Adapted from FMOH AND WORLD BANK 2006)

The private not-for-profit, often run by churches, does not have a significant proportion of facilities in the zones but for the South east zone where they have about $10 \%$ of the total. In all, there are private for profit hospitals in all the zones but they usually tend to be small while non-profit hospitals tend to be large. Implied in this is that private for-profit hospitals usually account for few bed capacity. It is equally necessary to state that most secondary health facilities, whether government-owned or private forprofit, are mainly located in the urban areas. In other words, health services 
are also privately financed and provided; just as there are examples in Nigeria of the existence of private finance with public provision. The consideration here is for user charges of fees in the context of the provision of health care. For example, health insurance is currently being used to purchase private as well as public health care (Atoyebi, 2005).

Another scheme is that public hospitals have introduced the policies of using public finance to purchase private services. In this regard, "contracting out'" has been the most commonly tried. This means that government purchases a service from an outside source, which provides the service using its own workforce and resources (Berman, 1997). Finally, there exists another pattern where the public releases their workforces, which are paid by the government, to work in private for-profit hospitals. An example is the case of Bishop Shanahan Hospital, Nsukka, which has some of her staff being paid by the State Ministry of Health. The results of these policies have been varied, according to the services being contracted.

As a matter of fact, evidence from states on PPP shows that the provision of catering, security, cleaning, laundry and mortuary services by private firms have been relatively successful (Ogundipe, 2005).

\section{The health sector and the existing characteristics of public-private partnership}

In the present institutional arrangements of the National health system, there is no interface or coordination between the activities of the public and private sectors on one hand and between health institutions in the public sector on the other. The situation is that of fragmented and uncoordinated health care services with private providers engaging in a large variety of health activities that are not integrated into the national health system. To this end, the National Health Policy strongly recommends an increased role for the private sector in service delivery. The policy permits the participation of the private for-profit and not-for-profit including health providers, religious and other voluntary organizations, communal bodies, and individuals in the provision and financing of health care services (FMOH, 2004). On the basis of the above, the National Policy on PPP was enunciated in 2005. The policy was developed in the context of National Economic Empowerment and Development Strategy (NEEDS), the Health System Reform Programme (HSRP), the MDGs, National Health Policy (2004), National Health Bill (2004), Reviewed National Health Insurance Scheme (2003) and the Blueprint for the Revitalization of the Primary Health Care (2004). The policy highlights the features that will ensure that both sectors complement each other in achieving national health sector objectives 
(FMOH, 2005). Some of the key principles for effective PPP action in the health sector are:

- Governments (federal, state and local) share the obligation to ensure an enabling environment for ensuring that all people are protected from harmful practices, and have rights as consumers of health services.

- $\quad$ Effective partnerships among private sector institutions, civil society organizations, and governments, will allow fulfillment of their social expectations without compromising core missions.

- $\quad$ There shall be on-going communication/interaction on health issues by all stakeholders in the public and private sectors. As part of such interactions and consultation, private sector organizations shall have opportunities to contribute to the planning and implementation of policy.

- $\quad$ There shall be decentralization of powers by government and acceptance of the expanded role of the private sector and the community.

- $\quad$ Part of the wider government obligation will include provision of basic amenities such as water supply, environmental sanitation and power supply.

Other features of the policy include various financing options, provision of care, regulatory framework, and human resources for health, roles of stakeholders and monitoring and evaluation for effective PPP (Federal Ministry of Health).

\section{Assessment of mdgs in relation to health services in nigeria}

In September 2000, 189 countries from across the world including Nigeria endorsed the United Nations Millennium Declaration in New York. This led to the adoption of the eight time-bound Millennium Development Goals (MDGs) and their monitorable indicators.

The eight goals were to be achieved by respective countries by 2015 and were stated as follows:

MDG 1: Eradicate extreme poverty and hunger

MDG 2: Achieve universal primary education

MDG 3: Promote gender equality and empower women

MDG 4: Reduce child mortality

MDG 5: Improve maternal health

MDG 6: Combat HIV and AIDS, malaria and other diseases

MDG 7: Ensure environmental sustainability

MDG 8: Develop a global partnership for Development.

From the above, it can be seen that the MDGs targets in relation to health include: Reducing child mortality; improving maternal health, combating HIV and AIDS, malaria and other diseases. In Nigeria, the implementation of the MDGs began when the Federal Government pledged 
to apply the savings from the Paris Club Debt Relief Deal in 2005 to propoor programmes and projects. Consequently, several policies, programmes and projects have thus been implemented as a result of savings from the external debt relief, with direct impact on the MDGs from then till 2015, the target year.

In assessing the progress so far made with regard to reducing child mortality, The 2015 End Point Report which is an historic assessment of the planning and implementation as well as the monitoring and evaluation of the entire experience and which further serves as a transitional document linking Nigeria's MDGs era and the post-MDGs development framework now officially known as the Sustainable Development Goals (SDGs), notes as follows:

"Nigeria's efforts aimed at reducing avoidable child deaths have been met with gradual and sustained progress. The under-five mortality rate (U5MR) has improved remarkably from 191 deaths per 1000 live births in 2000 to 89 deaths per 1000 live births in 2014 as the end-point status. Considering the end-point status of U5MR, Nigeria falls short of the 2015 target of 64 deaths per 1000 live births by $28 \%$. In 1990 (as the baseline), the infant mortality rate (IMR) was estimated at 91 deaths per 1000 live births. This, however, decreased to 75 deaths per 1000 live births in 2008 and to 61 deaths per

1000 live births in 2012. Although the end-point figure which stood at 58 deaths per 1000 live births in 2014 reflects progress, it is still short of the 2015 target of 30 deaths per 1000 live births. The immunization effort against measles has been relatively effective. It has resulted in significant reductions in case burden as a result of the scale up of the administration of measles vaccination to children 9 months and older through routine immunization services led by the National Primary Healthcare Development Agency (NPHCDA). The proportion of one-year-old children immunized against measles increased from $46 \%$ in 1990 to $61.3 \%$ in 2012 and subsequently to $63.0 \%$ in 2014 .

Nigeria has also recorded strong progress in the effort to eradicate polio and recently celebrated one year without polio from July 2014 to July $2015^{\prime}$.

With regard to improving maternal health, the 2015 End Point Report, notes:

"The drive to make progress on this goal has seen improvements in maternal health. With a baseline figure of 1000 deaths per 100,000 live births in 1990, the Maternal Mortality Rate (MMR) consistently decreased over the years to 545 in 2008 . The downward trend continued to 350 deaths per 100,000 live births in 2012 and subsequently to its end-point status of 243 per 100,000 live births in 2014. 
Many policy drivers made the progress possible; one being the Midwives Service Scheme while the other was the collaborative efforts made between donors and the Federal Ministry of Health and its parastatals. In the meantime, the proportion of births attended by skilled health personnel improved appreciably from a baseline figure of $45 \%$ in 1990 to the end-point status of $58.6 \%$ in 2014 with the conviction that the national figure would have been better had it not been for the wide disparities across states with lower records. The success recorded is attributed to effective implementation of the Midwives Service Scheme (MSS). In the case of antenatal coverage, significant progress was also recorded. Antenatal coverage of at least one visit recorded an end-point status of $68.9 \%$ in 2014 , and for at least four visits, the end-point status was $60.6 \%$ in 2014 . The successes imply the need for a scale-up of the policy interventions".

The 2015 End Point Report on the third target which is combating HIV and AIDS and other related diseases notes as follows:

"The prevalence of HIV among pregnant young women aged 15-24 years has steadily declined from $5.4 \%$ in 2000 to $4.1 \%$ in 2010 (end-point status). The decline resulted from the implementation of tested high impact interventions implying the need for consistent implementation of such high impact interventions in the sector. With respect to the incidence of tuberculosis per 100,000 people, the efforts have not produced appreciable results. In the past 7 years, the value for this indicator has fluctuated between 343.00 in 2005 and 339.00 in 2012. The end-point status of the incidence of tuberculosis in Nigeria was 338 as of 2013. This latest figure is still unacceptable and calls for renewed efforts, more resources and interventions in order to drastically reduce the prevalence of tuberculosis".

The overall conclusion on reducing child mortality is that strong progress has been made but goal not met while that of improving maternal health is that target is met and strong progress made on other indicators. For combating HIV and AIDS, assessment indicates that appreciable progress has been made but there is weak progress in other diseases. There is therefore urgent need for continued efforts in terms of partnerships between the public and private sectors of the economy in the provision of health services in Nigeria.

\section{Repositioning ppp for mdgs in nigeria}

As reflected earlier, both the public and private sectors are partners in delivering health care throughout the country. Given the mixed systems of health service delivery, financing and provision is a joint responsibility of all the stakeholders in the health sector. But, it is necessary to distinguish between the financing and provision of health services in the context of 
public-private partnership (WHO, 1991). First, health services are publicly provided in Nigeria, as it is the case in Namibia, South Africa, Sri Lanka and Spain. The federal government finances public sector tertiary services; states finance public sector secondary hospital services and local governments, with the collaboration of other private not-for-profit organizations also intervene at the PHC level.

Secondly, health services are also privately financed and provided. There are numerous private health facilities across the country for consumers who have the ability and willingness to pay. The decline in the quality of services provided at public health facilities precipitated the emergence and continued growth of private hospitals and clinics in Nigeria. The growth in number of these facilities has been so rapid that it is estimated that more people receive medical attention from them than from public facilities. According to WHO (2007), in 2004, private expenditure on health as a percentage of total expenditure on health stood at $69.6 \%$. This no doubt, must have risen far beyond the above figure.

As noted earlier, health care is either free or subsidized at public health facilities. But private care is only available on a fee-for-service basis. The rise in the proportion of care provided at private facilities has also meant an escalation in the cost of services and thus diminished access as the cost is unaffordable by most people. There is no social security programme (WHO, 2006), and until recently, there was not health insurance scheme in the country. Even then, in 2001, it was reported that only four private health insurance companies were operating in the country. Even then, in 2001, it was reported that only four private health insurance companies were operating in the country, with the largest covering around 18,000 people (Alubo, 2001). The services of these few private companies underwriting health insurance are grossly under-utilized due to high premiums.

All these high cost of health care exist, when a whopping $71 \%$ of Nigerians live below poverty line, on less than \$1/day (UNICEF, 2007) and are therefore not in a position to afford the high cost of health care. This means that millions are left without any form of coverage. As a result, concern has risen that continued growth in the number of people without coverage would further add to the downward spiral of key health indicators, and in addition, contribute to exacerbating an already appalling life expectancy rate; and the dismal performance of the country in the healthrelated MDGs targets. The import of the above is that the activities of health services, as presently obtained, cannot lead to the achievement of healthrelated MDGs targets. Therefore, achieving the MDGs will require not only global partnerships but also domestic public-private partnerships. With respect to health-related goals of reducing child mortality, improving maternal health and combating HIV/AIDS, malaria and other infectious 
diseases, greater cooperation, collaboration and assistance of the private sector is required in the face of serious resource constraints and enormous institutional challenges (FMOH 2004).

The major challenge is to generate sufficient political support for public private partnerships in Nigeria. Nigeria has made some considerable progress along the path of PPPs in the past few years. This was expressed through the privatization and deregulation programmes. Unfortunately, the federal government has not demonstrated its belief in the private sector as the engine of growth of the economy by disbursing part of the $\$ 1$ billion debt relief gains from the Paris Club of creditors which the federal government promised to channel to pro-poor programmes. Out of the one trillion naira initially released for MDGs, the sum of N750 billion was retained by the federal, while states got N250 billion. So far, the federal government has spent N174 billion of this amount from the debt relief gains in the health sector from 2006 to date as part of the efforts to attain the health Millennium Development Goals in the country (Asemota, 2011).

Again, it has to be noted that PPP is not a panacea for all the problems in the health sector, as there are challenges to be overcome in its implementation. In the absence of effective policy implementation, supplierdriven private sectors will operate parallel to the government sector in a way that serves primarily the financial and professional interests of private providers. Hence, government needs to establish procedures and mechanism for effective mediation between providers and consumers. This is required reconcile the conflicting interests.

The policy implementation strategy should encourage and maximize private sector (as provider) participation in the health sector for efficiency, to achieve the health targets of MDGs.

All the regulatory structures need to be reorganized and strengthened. For example, the State Commissioners of Health, should periodically inspect and asses health institutions (public and private) to ensure that standards are constantly kept for quality assurance. This is presently not effectively discharged and should be strengthened.

The Nigerian entrepreneurs are currently not mobilized for the achievement of the MDGs. They should be encouraged to imbibe the culture of corporate governance and best global practices. The same applies to other multi-national establishments in oil and gas, telecommunications etc.

Finally, a clear policy advocating the use of PPPs in the health sector as it is presently pursued in the wider economy of the nation, should be pursued, as well as the rationale for their use. The government at all levels should provide political commitment and support for the programme. It is important that policies stress that PPPs are being pursued to provide better 
services, not simply to attract private sector resources to supplement those that the government lacks. Certain policy also encourages the discussion of key issues among different stakeholders, furthering an increased understanding of the main characteristics of PPPs, their advantages, and their drawbacks. In addition, it may be important to look at other ways of developing an understanding of PPPs by policy makers, government officials and other stakeholders. As it is now, policy makers at state and local levels seem not to appreciate what PPP is all about.

\section{Conclusion}

Public-private partnership as financing model for physical and socioeconomic development has been in vogue for more than two decades in developed countries and South African. PPP has been used by developed countries as a financing strategy or option for public sector projects since about 1990. But, it was only last few years that Nigeria started creating an enabling environment for PPP as part of the socio-economic and political reform programmes.

The challenge is now finding mechanisms to harness the resources of the private sector to support public sector effort to promote national health objective, especially, the health-related targets of MDGs, now SDGs. Be that as it may be, it should be noted that the concept of Public-Private Partnership (PPP) goes beyond the rapprochement between the public sector and the private sector and the general willingness of the government to partner with the private sector for the rapid economic transformation of the innovative financing or procurement model for the construction, procurement or delivery of major infrastructure projects in key sectors of the economy, like the health sector.

This demands establishing a more effective framework for channeling and coordinating increased assistance. Worthy of note is that accelerated progress should be contingent on partnerships that are based on mutual trust, sharing of information, joint planning, policy formulation, implementation and evaluation, as well as joint financing of programmes and activities. The public and private sectors would also need to collaborate to improve quality by supporting innovation, improving information for quality monitoring, enhancing clinical and administrative management capacities, and reviewing national programmes and project support on MDGs.

To ensure consumer protection, government should enact appropriate consumer protection laws aimed at protecting consumers from monopolistic and unfair business practices that are direct consequences of market deregulation/privatization. However, governments are not without their failures. Bureaucratic management of diverse and dispersed health care facilities has often resulted in disappointing outcomes. For these reasons, 
there is need for government to strengthen the management of health care delivery at all levels.

The point of this paper is that now the Millennium Development Goals, MDGs has ended and we are now talking of sustaining them in the form of SDGs, there is a need to rethink reforms in Nigeria to produce a better national framework which harmonizes the initiatives of both the public and private sectors of the economy for sustaining the Sustainable Development Goals, SDGs in Nigeria. Through the National Economic Empowerment and Development Strategy (NEEDS), Nigeria has adopted a market-based, private sector driven economic system. Reforms have been geared towards providing the environment to achieve this objective. The market driven private sector based economy requires a sound management strategy to ensure a good mix with the public sector. Within the global context, Nigeria, like other developing countries, needs to modify her strategies to ensure the attainment of SDGs. The national strategy which should result from a rethink of current reforms on PPP, would provide relevant basis for meeting development objectives, especially, the SDGsrelated health targets.

\section{References:}

1. Alubo, O. (2007). "The Promise and Limits of Private Medicine: Health Policy Dilemmas in Nigeria' ': Health Policy and Planning 16 (3).

2. Asemota, A. (2011). FG Spent, N174bn debt relief Money in Health Sector-MDG Adviser Daily Sun, October, $31^{\text {st }}$.

3. Atoyebi, W. (2005). "Public-Private Partnership in the Provision of Health Services: Stewardship and Quality Assurance". Paper Presented at the National Consultative Workshop on Public-Private Partnership in Nigeria, 30 March - $1^{\text {st }}$ April 2005.

4. Berman, P. (1997), "Supply-Side Approaches to Optimizing Private Health Sector Growth. In Newbrander W. (Ed.) Private Sector Growth in Asia: Issues and Implications. Chichester: John willy and Son.

5. Dutta, Arin. Eddie Kariisa, John Osika, Gilbert Kombe, Ali Johnson Onoja, Muhammed Lecky, Akin Oyemakinde (2009). The Private Health Sector in Nigeria - An Assessment of Its Workforce and Service Provision. Bethesda, MD: Health Systems 20/20 project, Abt Associates Inc.

6. Federal Republic of Nigeria (2004). Nigeria Millennium Development Goals 2005 Repot. Abuja: National Planning Commission. 
7. Federal Republic of Nigeria (2006). Nigeria Millennium Development Goals 2005 Report. Abuja: National Planning Commission.

8. Federal Ministry of Health (2004). National Health Policy NHP. Abuja: Federal Ministry of Health.

9. Federal Ministry of Health (2004). Achieving Health-Related Millennium Development Goals in Nigeria: A Report of the Presidential Committee on Achieving Millennium Development Goals in Nigeria: Abuja. FMOH.

10. Federal Ministry of Health (2005). National Policy on Public-Private Partnership for Health in Nigeria, National Consultation Workshop on Public-Private Partnership in Nigeria, 30 March $-1^{\text {st }}$ April, 2005.

11. Federal Ministry of Health (2015). Nigeria 2015 Millennium Development Goals End-Point Report, Abridged Version. Office of the Senior Special Assistant to the President on MDGs.

12. Hargreaves, S. (2002). "Time to Right the Wrongs: Improving Basic Health Care in Nigeria" The Lancet, No. 2030.

13. Hofman, M. (1999). The Role of Public-Private Partnership in Expanding Urban Environment Services. Germany: UNDP Bureau for Development Policy.

14. International Finance Corporation (IFC), (2007a). The Business of Health in Africa: Partnering with the Private Sector to Improve People's Lives. Washington DC: World Bank.

15. Matazu, A. (2005). Assessing the Legal and Regulatory Policies of Public Health in Nigeria. Paper Presented at National Consultative Workshop on Public-Private Partnership in Nigeria, 30 March - 1 April, 2005.

16. National Bureau of Statistics (2007). Nigeria Poverty Assessment 2007. Abuja: NBS.

17. Nnamuchi, O. (2007). The Right to health in Nigeria http://www.abdn.ac.uk/law/hhr.shtml

18. Ogundipe, M. (2005). Public-Private Partnership in the Provision of Health Services in Nigeria. Paper Presented at National Consultative Workshop on Public-Private Partnership in Nigeria, $30^{\text {th }}$ March $-1^{\text {st }}$ April, 2005.

19. Oxfam International. February 2009. Blind Optimism: Challenging the myths about private health care in poor countries. Briefing paper $\# 125$.

20. Preker, A and .A. Harding (2000). The Economics of Public and Private Roles in Health Care: Insight from Institutional Economics and organizational Theory HNP Discussion Paper, June 2000, Washington DC: World Bank. 
21. Transparency International (2004). The National Integrity System TI Country Study Report Nigeria 2004. Berlin: Transparency International.

22. UNICEF (200). At a Glance: Nigeria available at http://www.unicef.org/infobycountry/nighera.statistics.htmlaccessedo n7June2007.

23. United Nations (2010). Human Development Report. New York: United Nations.

24. WHO (2006). The World Health Report 2006. Geneva: Palgrave Macmillan/UNDP.

25. WHO (2007). Health Financing and Social Protection available at htt://ww.who.int/countries/nga/areas/health

26. financing/en/index.html,accessedon20august,2007

27. WHO (2007). World Health Statistics 2007. Genera: WHO.

28. WHO (1991). The Public/Private Mix in National Health Systems and their Role of Ministries of Health, Report of a Meeting held in Mexico; July 20-26, 1991. Genera: Division of strengthening of Health Services.

29. Widdus, R. (2001). "Public-Private Partnerships for Health: Their Main Targets, Their Diversity, Their Future, Directions'" Bulletin of the World Health Organization 79 (8).

30. World Bank (2005). Nigeria: Health, Nutrition and Population Country Status Report. Washington, DC: World Bank. 